\title{
Malignant Adrenal Gland Composite Pheochromocytoma
}

National Cancer Institute

\section{Source}

National Cancer Institute. Malignant Adrenal Gland Composite Pheochromocytoma. NCI Thesaurus. Code C92184.

An adrenal gland composite pheochromocytoma that metastasizes to other anatomic sites. 